\title{
Application of Horizontal Well Geological Optimization Design in BH Oilfield
}

\author{
Run Zhang ${ }^{1}$, Xin Zhang ${ }^{2}$, Zicheng Zhang ${ }^{2}$, Zhaoting $\mathrm{Li}^{2}$, Wen Ren ${ }^{2}$ \\ ${ }^{1}$ CNOOC EnerTech-Drilling\& Production Co., Ltd, Tianjin, China \\ ${ }^{2}$ CNOOC (China) Co., Ltd. Tianjin Branch, Tianjin 300452, China
}

\begin{abstract}
Drilling geological design is the basis of various geological work in the drilling process and the embodiment of the specific deployment of oil and gas exploration and development. In order to improve the scientificity, economy and operability of horizontal well geological design, the key technologies of horizontal well drilling geological design in BH oilfield development process are discussed, such as formation prediction technology, formation pressure prediction technology, and complex engineering situation prediction technology, which have certain guiding significance for horizontal well geological design.
\end{abstract}

Keywords: Horizontal well, Geological optimization design, BH oilfield.

\section{Introduction}

$\mathrm{BH}$ oilfield is a heavy oil reservoir with edge and bottom water, with oil-bearing area of $12.7 \mathrm{~km}^{2}$, geological reserves of $2168.82 \times 10^{4} \mathrm{t}$, recoverable reserves of $538.99 \times 10^{4} \mathrm{t}$, and calibration recovery factor of $24.9 \%$. There are 4 sets of oil bearing strata, mainly Guansan oil group and Guan2 oil group, followed by Guanyi and Shahejie, reservoir depth 1206 - 1434 m. Kongdian oilfield belongs to high porosity and high permeability reservoir, the average porosity is $33 \%$, air permeability is $2209 \times 10^{-3} \mathrm{um}^{2}$. The average density of crude oil is $0.9655 \mathrm{~g} / \mathrm{cm}^{3}$, the viscosity of underground crude oil is $72.09 \mathrm{mPa} \cdot \mathrm{s}$, and the viscosity of ground degassing crude oil is $1054.46 \mathrm{mPa} \cdot \mathrm{s}$. Horizontal well technology has become an important means to achieve effective development of such reservoirs. So far, there are 139 oil wells in Kongdian Oilfield, the daily production level is 444t. Among them, 30 horizontal wells, the daily production level of $157 \mathrm{t}$, accounting for $35.4 \%$.

The production of ordinary vertical wells is low and it is difficult to achieve development benefits. Therefore, horizontal wells are mostly used for development. Horizontal wells have long horizontal sections and large contact area with reservoirs, which can significantly improve single well production. The wellbore structure of horizontal well is different from ordinary vertical well. Due to the special wellbore structure, higher requirements are put forward for field drilling and geological logging. Strengthening the geological design of horizontal well is of great significance to improve the success rate of horizontal well drilling.

\section{Advantages of Horizontal Well Development}

Horizontal wells usually refer to oil and gas wells with horizontal section inclination greater than $86^{\circ}$. The wellbore structure of horizontal wells is different from that of vertical wells. Horizontal wells usually have a long horizontal section. By controlling the trajectory of horizontal wells, the horizontal section can pass through the reservoir, thereby increasing the contact area between the wellbore and the reservoir, increasing the oil control range, increasing the oil drainage area, increasing the single well efficiency range, and increasing the production effect. Studies have shown that under the same geological conditions, horizontal well production is more than three times that of ordinary vertical wells, which can significantly enhance the development efficiency. Because the development horizon of horizontal well is a set of reservoir, the elevation drop of wellbore trajectory is small, and the production pressure difference is low. In the development of gas cap reservoir or bottom water reservoir, it can effectively slow down the bottom water or gas cap coning, and can achieve better development effect. Horizontal wells have a good effect on the development of thin oil layers. This reservoir uses vertical wells to produce small contact areas, low production, and poor economic benefits. Horizontal wells can significantly improve development efficiency. In addition, horizontal wells can drill multiple wells at one position on the ground, which can control a large range, reduce ground construction and land occupation, and protect the environment.

\section{Horizontal Well Drilling Geological Design Process}

Preparation before design. The preparation work before design is the basis for completing the design. The preparation work before design mainly includes familiarizing with the block data, understanding the purpose of designing horizontal wells, designing the geographical location of wellheads, ground conditions, and structural parts; analysis of block data, mainly drilling data, adjacent well data, logging data, seismic data, block research reports, a variety of maps, including geographical location maps, structural maps, single well histogram, reservoir profile, etc.

Horizontal well geological design process. After the preparation work is completed, the geological design of horizontal wells enters the design stage. The main work flow is as follows: according to the research situation of horizontal well design, the geological conditions of the design well area are determined, the drilling purpose and target horizon of the design well are clarified, the formation lithology and oil and gas reservoir position encountered by the design well are 
predicted, the drilling fluid type and performance requirements are designed according to the formation situation, the reservoir protection design is carried out, the layers, requirements, application technology series and drilling core design of geological logging data are designed, the wellbore trajectory of the horizontal well is determined, the wellbore structure, casing program, drilling engineering warning and formation pressure prediction are designed, and various design drawings are attached.

Horizontal well geological design content. According to industry requirements and relevant regulations of oil companies, drilling geological design should include the following contents: basic design data of horizontal wells, regional geological survey, basis and purpose of design, prediction of formation encountered by horizontal wells and lithology development, prediction of oil-gas-water interface, formation pressure prediction, type and performance requirements of design drilling fluid, interval of design geological logging data, requirements of logging data, application technology series, coring design, wellbore quality and structure design, drilling engineering accident warning, and attached various drawings and data tables.

\section{Key Points of Horizontal Well Geological Design}

With the continuous maturity and improvement of drilling geological design technology, a series of geological design technologies have been formed, such as stratum stratification prediction technology, stratum pressure prediction technology, and engineering complex situation prediction technology.

\subsection{Strata Stratification Prediction Technology}

Formation profile prediction is one of the important contents of geological design, which is of great significance for geological tracking while drilling, stratigraphic correlation, oil and gas reservoir prediction, horizontal well trajectory design, geological guidance and logging data acquisition. The prediction of stratigraphic stratification is carried out from the following aspects: (1) According to the designed horizontal well location, the geological data of the block, the stratified data of adjacent wells, and the seismic data are collected to establish the study area; (2) Secondly, the regional geological data and adjacent well drilling data are analyzed to find out the location of regional marker layer and standard layer. According to the adjacent well logging data, the development of stratum lithology is analyzed, and the response characteristics of logging curve are analyzed to carry out regional stratigraphic correlation. (3) Detailed layered correction is carried out on the drilling data of adjacent wells, the seismic reflection characteristics of typical lithology are analyzed in the seismic data volume, and the identification method of seismic phase type is established. The well seismic calibration is carried out on the corrected single well layered, and the seismic layered interpretation is carried out by tracking the layer reflection characteristics in the seismic data volume. The layered depth data of designed horizontal wells are obtained by establishing the time-depth relationship. (4)
According to the formation contact relationship, fault development and adjacent well geological stratification, horizontal well stratification design is carried out; (5) Through the analysis of regional reservoirs and gas reservoirs, combined with the development of drilled oil, gas and water layers and test production data, the profile maps of oil and gas reservoirs are established, and the reservoir development is predicted by reservoir inversion and other technologies. The horizontal well trajectory is loaded into the prediction model to obtain the reservoir development in the design horizontal trajectory direction. (6) drawing various maps, mainly stratigraphic correlation map, the target layer top and bottom surface structure map; the horizontal well trajectory direction reservoir prediction map provides horizontal well layered prediction data.

\subsection{Horizontal Well Formation Pressure Prediction Technology}

Formation pressure prediction is an important part of geological design, which is of great significance for preventing engineering accidents and optimizing drilling fluid design. For the prediction of formation pressure, it is necessary to collect regional geological, seismic and logging data, as well as the formation pressure data of adjacent wells and the use of drilling fluid, and conduct a comprehensive analysis. Combined with the pressure detection data of adjacent wells, the formation pressure of design wells is theoretically calculated. Then, it is necessary to analyze the lithology characteristics and sensitivity parameters of horizontal wells, and carry out the pressure analysis and judgment of horizontal wells in combination with the drilling fluid performance and application of adjacent wells. According to the formation pressure distribution, the current well formation pressure coefficient is obtained, the drilling fluid performance design is optimized according to the pressure situation, and the reservoir protection measures are formulated.

\subsection{Prediction of Complex Engineering of Horizontal Well}

Drilling construction is a high-risk operation. It is not only complicated in construction process, but also faced with various complex geological conditions, which is prone to engineering accidents. Once an engineering accident occurs, it will delay the progress of drilling construction, increase the cost of drilling construction, and affect the drilling efficiency. In particular, it will in immeasurable economic losses and adverse social impacts. Therefore, it is necessary to strengthen the prediction of complex engineering conditions and improve the safety of drilling construction. Horizontal well complex engineering prediction technology as shown in Figure 3, first of all to collect block geological data, logging data, adjacent well drilling engineering data, production pressure data, comprehensive analysis; secondly, the characteristics of formation fluid, regional formation pressure, formation lithology, formation temperature and pressure variation are analyzed to obtain the regional formation pressure. Again, the adjacent well formation pressure, formation compaction, gas analysis, combined with fault development, abnormal 
pressure distribution, formation porosity, water absorption characteristics, determine the complex pressure; then, according to the adjacent well geological logging experience, drilling construction experience, combined with pressure prediction results, relevant standards and norms, formulate engineering preventive measures; finally, according to the special fluid situation and the engineering accident situation of adjacent wells, the engineering accident prompt is formulated, and the prediction of engineering complexity is obtained.

\section{Conclusion}

Drilling geological design is the basis of various geological work in the drilling process and the embodiment of the specific deployment of oil and gas exploration and development. It is of great significance to guide drilling construction, reduce drilling risks, and improve operational efficiency. At the same time, it also directly affects the quality of logging data and drilling construction costs. Drilling geological design requires scientificity, economy and operability. Only by constantly optimizing drilling geological design to meet the geological and engineering conditions and the actual needs of drilling construction can it play a role in the drilling process.

\section{References}

[1] Zhao Feng. Research on horizontal well rotary deflection drilling tools[J]. Western Exploration Engineering, 2021, 33(10): 45-46+49.

[2] Zhang Xiaofan. Study on borehole trajectory design and control technology of deep horizontal wells in Daqing $[\mathrm{J}]$. Western Exploration Engineering, 2021, 33(09): 54-56.

[3] Yang Li. Key points of reservoir engineering technology in water well development[J]. Chemical Engineering and Equipment, 2021(07): 95-96.

[4] Zhang Shengfeng. Research and Application of Horizontal Well Cementing Technology[J]. Cleaning World, 2021, 37(06): 151-152.

[5] Deng Xianwei, Chen Yusi, Chen Chao. Optimization of Fracturing Process Parameters for Horizontal Wells in Tight Sandstone Gas Reservoirs[J]. Petrochemical Technology, 2021, 28(06): 153-154.

[6] Luo Wei, Wang Zhenfeng, Liu Zhentao, Chen Changjie, Liu Quanbao, Wang Fengying, Sun Tao. Optimal design of ICD completion for water injection horizontal wells in different types of reservoirs[J]. China Offshore Oil \& Gas, 2021, 33(03): 135-146.

[7] Lu Yanmin. Causes and Countermeasures for Partial Wear Operation in Horizontal Wells[J]. Chemical Engineering and Equipment, 2021(06): 80-81+96.

[8] Wang Tai, Liu Haixiao, Liu Dongdong, Qiu Xiaohua, Wang Bo. Discussion on the status quo and development trend of horizontal well completion technology[J]. China Petroleum and Chemical Standards and Quality, 2021, 41(11): 156-157. 